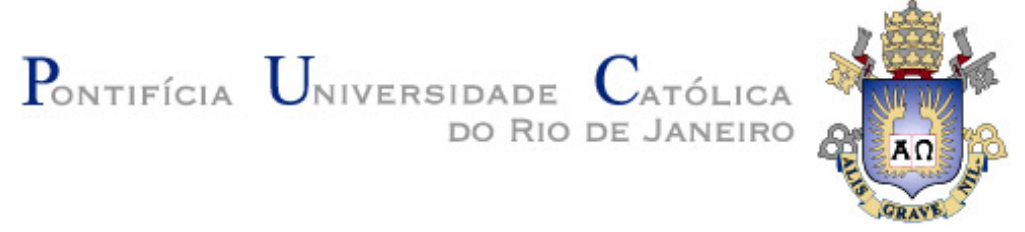

Marcio Luiz Coelho Cunha

Redes Sociais Dirigidas ao Contexto das Coisas

Dissertação apresentada ao Programa de Pós-graduação em Informática da PUC-Rio como requisito parcial para obtenção do título de Mestre em Informática.

Orientador: Prof. Hugo Fuks

Rio de Janeiro

Agosto de 2010 


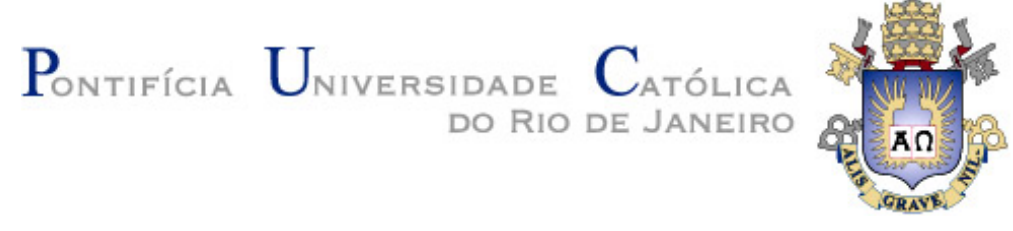

Marcio Luiz Coelho Cunha

\title{
Redes Sociais Dirigidas ao Contexto das Coisas
}

Dissertação apresentada como requisito parcial para obtenção do grau de Mestre pelo Programa de Pós-graduação em Informática da PUC-Rio. Aprovada pela Comissão Examinadora abaixo assinada.

\author{
Prof. Hugo Fuks \\ Orientador \\ Departamento de Informática - PUC-Rio \\ Prof. Alberto Barbosa Raposo \\ Departamento de Informática - PUC-Rio
}

Prof. Gustavo Robichez de Carvalho

Departamento de Informática - PUC-Rio

Prof. José Eugenio Leal Coordenador Setorial do Centro Técnico Científico - PUC-Rio

Rio de janeiro, 26 de agosto de 2010 
Todos os direitos reservados. É proibida a reprodução total ou parcial do trabalho sem autorização da universidade, do autor e do orientador.

\section{Marcio Luiz Coelho Cunha}

Graduou-se em Engenharia de Computação pela PUC-Rio. Desenvolveu como projeto de mestrado uma rede social dirigida ao contexto das coisas - PUC-Rio na área de IHC e Engenharia de Softwares.

Ficha Catalográfica

Cunha, Marcio Luiz Coelho

Redes Sociais Dirigidas ao Contexto das Coisas / Marcio Luiz Coelho Cunha; orientador: Hugo Fuks - Rio de Janeiro : PUC-Rio, Departamento de Informática, 2010

v., 72 f: il. ; 29,7 cm

1. Dissertação (mestrado) - Pontifícia Universidade Católica do Rio de Janeiro, Departamento de Informática.

Inclui referências bibliográficas.

1. Informática - Dissertação. 2. IHC. 3. Rede Social. 4. Mobile Web. 5. Internet of Things. I. Fuks, Hugo. II. Pontifícia Universidade Católica do Rio de Janeiro. Departamento de Informática. III. Título 
Dedico esse trabalho aos meus pais, Luiz Octavio e Marcia Maria, que se empenharam para me dar a melhor educação possível e a minha esposa, Ana Paula por me apoiar e estar sempre ao meu lado. 


\section{Agradecimentos}

À Deus por inspiração e ensinamentos de superação.

À minha querida esposa, Ana Paula, pela compreensão, companheirismo, carinho e paciência nestes últimos anos.

Ao meu orientador, professor Hugo Fuks, pelo incentivo ao desenvolvimento deste trabalho, pelas valiosas discussões, críticas e sugestões. Obrigado por sempre me motivar a fazer algo diferente.

Aos meus pais, Luiz Octavio e Márcia Maria pela amizade, carinho e por me ensinar a nunca desistir.

Aos meus avós Guilherme e Eglair pelo amor e apoio.

Aos meus amigos e companheiros de trabalho no projeto da WineTag, Gustavo, Bruno, João e Josemar pela determinação, amizade, trabalho em conjunto. Obrigado por acreditar e viajar comigo nesse sonho. 


\section{Resumo}

Cunha, Marcio Luiz Coelho; Fuks, Hugo. Redes Sociais Dirigidas ao

Contexto das Coisas. Rio de Janeiro, 2010. 72p. Dissertação de Mestrado

- Departamento de Informática, Pontifícia Universidade Católica do Rio de Janeiro.

A cada dia mais e mais brasileiros possuem um telefone celular de última geração com conexão à internet. Estes novos aparelhos são capazes de ler diferentes tipos de etiquetas usadas para armazenar, recuperar e gerenciar informações, e estão conosco em toda parte para apoiar nossas tarefas diárias. Estes pequenos computadores são conscientes de seu entorno, e propícios à comunicação e colaboração com o mundo real. Devido a sua popularidade, disponibilidade e massa crítica de usuários atingida, novos serviços são desenvolvidos baseados no conceito da computação ubíqua, onde computadores e seres humanos são unificados em torno da noção de ambiente. Estes sistemas pervasivos lidam com questões de interação de contexto e reconhecimento de ambientes, e se adaptam de acordo com as preferências do usuário. Nesta dissertação são descritos o desenvolvimento e testes de usabilidade de uma rede social que é fundamentada nos conceitos da computação ubíqua e Internet das Coisas. Esta rede social, dirigida para o tema da enogastronomia, é acessível por dispositivos móveis e utiliza códigos de duas dimensões colados nas garrafas dos vinhos para através do software e da câmera do celular trazer informações de acordo com o contexto do objeto, lugar e preferência do usuário.

\section{Palavras-chave}

Redes Sociais; Internet das Coisas; Internet Móvel; Comércio Eletrônico 


\section{Abstract}

Cunha, Marcio Luiz Coelho; Fuks, Hugo. Context Driven Things Social Network. Rio de Janeiro, 2010. 72p. MSc Dissertation - Departamento de Informática, Pontifícia Universidade Católica do Rio de Janeiro.

Every day more and more Brazilians have a next generation mobile phone with an internet connection. These new devices are able to read different types of labels used to store, retrieve and manage information; they are with us everywhere to support our daily tasks. These small computers are aware of their surroundings and propitious to communication and collaboration with the real world. Due to their popularity, availability and critical mass of users reached, new services are developed based on the concept of ubiquitous computing, where computers and humans are unified around the concept of environment. These systems deal with issues of pervasive interaction of context, recognition of environments and adapt according to user preferences. This thesis presents a description of the development and usability testing of a social network that is based on the concepts of ubiquitous computing and the Internet of Things. This social network, addressed to the theme of enogastronomy, is accessible by mobile devices and uses twodimensional codes pasted on the bottles of wine for using the software and the phone's camera to bring information in accordance with the context of the object, place and user preference.

\section{Keywords}

Social Networks; Internet of Things; Mobile Web e-Commerce 


\section{Sumário}

1. Introdução

2. Justificativa

3. Projetos Relacionados 19

3.1. Auto-ID Labs do MIT 19

3.2. Future Internet - Service Web $3.0 \quad 20$

3.3. Facebook 21

3.4. Amazon 23

3.5. Projetos Enogastronomicos 24

4. Etiquetas Inteligentes 26

4.1. QR Code 28

4.1.1. A estrutura do QR Code 29

4.1.2. Características do QR Code 30

4.1.3. A decodificação do QR Code 30

4.1.4. Método de Segmentação de Otsu 32

4.1.5. Detecção de pontos que indicam o alinhamento 32

4.2. Criação de Dados para o QR Code 34

5. Internet das Coisas $\quad 37$

5.1. Web Semântica e a Internet das Coisas 37

6. Mobile Web 41

6.1. Informações Móveis com Contexto 41

6.2. WineTag Mobile 42 
7. A Rede Social WineTag 45

7.1. O Sistema 45

7.2. Sistema de Recomendação 48

7.3. Navegação e sistema de procura 50

8. Testes de Usabilidade 52

8.1. Estudo de Usabilidade 56

8.1.1. Sucesso da Tarefa 57

8.1.2. Comparação de Produtos 59

8.1.3. Experiência de Usabilidade Positiva 59

8.2. Resultados do Estudo de Usabilidade 61

9. Conclusão e Trabalhos Futuros 67

9.1.Próximas melhorias para o sistema 68

10. Referências Bibliográficas 70 


\section{Lista de figuras}

Figura 1 - Fluxograma para obter informações pelo celular 15

Figura 2 - Aparelho com nota de vinhos Wine Master 15

Figura 3 - Botão "Like" do Facebook com marcação semântica sobre 22 restaurantes na WineTag

Figura 4 - Tipos de etiquetas de duas dimensões 27

Figura 5 - Estrutura do QR Code 29

Figura 6 - Padrões de Marcadores $\quad 29$

Figura 7 - Foto de um QR Code tirada de um celular HTC G1 30

Figura 8 - Representação das vizinhanças de um pixel 31

Figura 9 - Rotação para posicionamento correto do QR Code 33

Figura 10 - Pirâmide de dados, informação, conhecimento e sabedoria 35 (DIKW)

Figura 11 - Ficha Técnica do vinho no site da WineTag 36

Figura 12 - Aplicativo web que usa bibliotecas jQuery e funções do 43

Web Kit para ter as mesmas funcionalidades que aplicativos nativos do iPhone

Figura 13 - Relação e propriedade das entidades 46

Figura 14 - Opção para editar texto sobre uma região vitivinícola fran- 46 cesa

Figura 15 - Ficha Analítica Descritiva de Avaliação do Vinho 47

Figura 16 - Ficha de cadastro e características de prato 48

Figura 17 - Componente de recomendação de vinhos relacionados 49

Figura 18 - Recomendação de harmonização prato e vinho 50

Figura 19 - Menu de navegação do site da WineTag 50

Figura 20 - Modelo de Ciclo de Vida da Engenharia de Usabilidade $\quad 53$

Figura 21 - Primeiro modelo da interface da WineTag em Microsoft $\quad 54$

Visio 
Figura 22 - Segunda versão da interface e programação da interface

da home page após testes com usuários

Figura 23 - Layout final da home page da WineTag

Figura 24 - Gráfico do nível de sucesso do site baseado na ajuda para 61 completar a tarefa

Figura 25 - Gráfico do nível de sucesso do aplicativo web do iPhone baseado na ajuda para completar a tarefa

Figura 26 - Gráfico do nível de sucesso do aplicativo nativo do iPhone baseado na ajuda para completar a tarefa

Figura 27 - Gráfico do tempo médio para completar as tarefas no site 63

Figura 28 - Gráfico do tempo médio para completar as tarefas no iPho- 63 ne com o aplicativo web

Figura 29 - Gráfico do tempo médio para completar as tarefas no iPho- 64 ne com o aplicativo nativo

Figura 30 - Gráfico de comparação de eficiência dos aplicativos

Figura 31 - Gráfico do nível de satisfação com a interface dos site. As barras de erro representa um intervalo de $95 \%$ de confiança Figura 32 - Gráfico do nível de satisfação com a interface no iPhone com o aplicativo Web. As barras de erro representa um intervalo de 95\% de confiança

Figura 33 - Gráfico do nível de satisfação com a interface no iPhone 65 com o aplicativo Nativo. As barras de erro representa um intervalo de 95\% de confiança

Figura 34 - Pontuação média do SUS. As barras de erro representa um 66 intervalo de $95 \%$ de confiança

Figura 35 - Aplicativo no iPhone exibindo as informações lidas no QR 67 Code

Figura 36 - Tela Tag Screen: Computador all-in-one que decodifica 68 dados do vinho contido no QR Code das etiquetas para indicar produtos relacionados através de uma web cam embutida Figura 37 - Contribuições de qualidade atraem mais atenção, o que gera mais recompensa, que inspira mais contribuições de qualidade 


\section{Lista de tabelas}

Tabela 1 - Descrição RDF do vinho Cobos Felino Malbec, $2008 \quad 39$

Tabela 2 - Tipos para os metadados do Open Graph 39

Tabela 3 - Itens de comparação vinho e comida 50

Tabela 4 - Ficha de descrição do cenário das tarefas do estudo de u- 58 sabilidade

Tabela 5 - Questionário de avaliação de usabilidade (SUS) 60 
A mente que se abre a uma nova ideia jamais voltará ao seu tamanho original. 